\title{
Could Fewer Teams Make a League More Competitive? The Portuguese Football League Case
}

\author{
By Daniel Magueta* \\ Sérgio Gonçalot \\ Carmen Guimarãest \\ Pedro Pego ${ }^{\bullet}$
}

\begin{abstract}
The competitive balance of professional sports leagues has been a topic of interest in the area of sports economics. Our work aims to contribute to this field of research. Naturally, supporters' expectations are that their club wins every game, but when a league becomes too unbalanced and its winner and all the other standings of interest are early known, that league tends to lose the supporters' attention. The uncertainty of the results and of the final standings is a key factor in the attractiveness of every league. With the expectation of turning the Portuguese Football League more attractive, in 2006/07 the championship suffered a reduction in two contending clubs, from 18 to 16 teams. In our study we analyze the impact that this two-team reduction had on the competitiveness of the Portuguese league. In order to do this we have analyzed the standings of the League since 1991/92 and applied different methodologies to measure the competitive balance. We conclude that this measure does not improve the degree of competiveness expected by the league executives.
\end{abstract}

Keywords: Competitive balance, Concentration indices, League size, Sports economics.

\section{Introduction}

The competitive balance, defined as the degree of strength parity between teams, of professional sports leagues has been a topic of interest in the area of sports economics and several studies have been conducted with the intention of measuring it. Our work aims to contribute to this field of research.

Professional football is by far the biggest professional sport worldwide. The four major European leagues (Premier League, Bundesliga, La Liga and Seria A) have generated a revenue in the $2012 / 13$ season of $\$ 8,800$ million, surpassing American Football in more than $\$ 1,500$ million (Jones et al. 2014)

The Portuguese league has generated $\$ 298$ million in 2011/12. Although this is far from the $\$ 2,000$ million generated by the Bundesliga, in relative

\footnotetext{
${ }^{*}$ ESTGA - University of Aveiro, Portugal.

${ }^{\dagger}$ Faculty of Economics - University of Coimbra, Portugal.

${ }^{\ddagger}$ ESAN - University of Aveiro, Portugal.

- Faculty of Economics - University of Coimbra, Portugal.
} 
terms to the Portuguese economy, it has a much greater impact when compared to the country's GNP. We may say that in Portugal football is the (only) national sport and the only truly professional one. Contrary to other countries, where there are other relevant sports nationwide (e.g. Rugby in England and France, Basketball in Spain, Greece or Turkey), in Portugal no other sport even approaches football in several key indicators such as attendance, television rights, players' salaries, sponsorships, etc.

Naturally, supporters' expectations are that their team wins every game, but when a league becomes too unbalanced and its winner and all the other standings of interest (Champions League and Europa League competitions access and relegation to lower divisions) are early known, that league tends to lose the fans' attention (lower attendances, lower television rates, etc.). The doubt on match results and indecision about a league's final standings is undoubtedly a crucial feature in supporter attraction, not only in football, but in every professional sport. The fact that football is very unpredictable is considered by many fans as one of the reasons that makes them love the game so much. In fact, Stefani (1980) studied the predictability in different sports, and found that football results are more random than the results in other sports, due to the relatively low number of goals, allowing chance to have more influence in the final score. Another important feature to attract people to a stadium is how well the game is actually played by the "performers", that is, how good is the spectacle provided by the teams in action?

With the expectation of making the Portuguese Football League more attractive, in 2006/07 the championship suffered a reduction in two contending clubs, from 18 to 16 teams. The main argument behind this measure was precisely the possibility that this reduction could increase the league's competitive balance, since each team would have more money, hire better players, and make the results more uncertain, at least in theory. Studies like the ones made by Borland and MacDonald (2003), Szymanski (2003) and Fort and Maxcy (2003), analyzed how competitive balance influences attendance.

Leagues with low competitive balance, resulting in the same teams achieving the top places, will tend to be even less competitive in the future. This happens precisely due to the monopolization of presences in the Champions League by the same teams in a country. The revenues a club can obtain through the results they achieve in the competition, the better sponsorship contracts, merchandizing and television rights allow them to become wealthier than teams with no regular access. As a result, even average teams are worried that this inequality in income access may lead to a decrease in their capabilities of beating strong teams.

In our study we analyzed the impact that a two-team reduction had on the competitiveness of the Portuguese league, and if this reduction had the effect expected and contributed to bridge the gap between the strong three teams (FC Porto, SL Benfica and Sporting CP) and the others. In order to study this topic, we have analyzed the League's standings since 1991/92.

The structure of the paper is as follows: next two sections present the literature review on studies focused in measuring competitive balance and the 
concentration models were used in the analyses. Last, we focus on the results and their discussion, and finally, give some brief concluding comments and directions for further research.

\section{Studies on Competitive Balance}

In this section we try to yield a summary of some previous studies made on the subject of competitiveness of sports championships. Several models and methodologies have been used to measure the competitive equilibrium (competitive balance) in different sports, some of them being very heterogeneous. One of the most widely used is the standard deviation of the ratio of the wins percentage relative to the ratio of the ideal victories percentage (Zimbalist 2002). There are other models and methodologies extensively used as measures of competitive balance, such as the Gini coefficient for the percentage of wins (Schmidt and Berri 2001), the Herfindahl-Hirshman Index (HHI) of competitive equilibrium, the concentration ratio approach, the ratio of the top to bottom win percentages or the index of divergence. In their work, Mizak et al. (2005) put together a comparison amongst different indices.

The use of economic concentration measures is not unexpected, since competitive balance is related to the balance and results of the championships, and it is possible to make some analogies with firms' market shares. Horowitz (1997) used relative entropy as a measure of concentration to study changes in the competitive balance in Major League Baseball. The author concluded that during the 20th century, there was a growth in the balance tendency, even though there were some occasional episodes which contributed to an imbalance.

Since competitive balance, especially in professional sport leagues, is essential to attract and maintain the interest of supporters and potential investors, its promotion is a main concern by the competitions organizers'. Nevertheless, Cannes (1974) showed that if all the teams have the same strength, this will not lead necessarily to a greater well-being of the spectators, so some degree of inequality between teams must be optimal. With another approach, but also leading to the natural existence of imbalanced leagues, Quirk and El Hodiri (1974) justified it by an endogenous different potential in "franchises" (teams), affecting factors such as the utility and profit functions.

Studies in the context of European football leagues are not as usual as the ones made in North American professional leagues, such as baseball, basketball, hockey and American football. Studying the evolution of five professional leagues in the United Sates, Quirk and Fort (1992) measured the competitive balance using methods based on the variance/standard deviation of wins percentage, for each league and in each year. They compared the observed wins percentage with the ideal win percentage (in a perfectly competitive league). They also used the Gini coefficient to study the concentration of each league in every season. For the five sports studied, the 
authors concluded that there is a competitive imbalance in all of them, although, in recent years, a significant progress has been observed in baseball.

In a work applied to the competitive balance of American college football, Bennett and Fizel (1995) studied the effects that the regulation/deregulation of television broadcasts had on the league. They followed the same methodology developed by Noll (1991) and Scully (1989) for measuring the competitiveness by comparing observed performance with the expected one, achieved if all teams had the same level.

Dorian et al. (2007) analyzed Major League Baseball and used the HHI applied to the percentage of wins. The authors found that different team numbers in a league affect the lower and upper bound of the index. They used a modified version of the HHI, corrected for the size of the league developed by Depken (1999).

In a more sophisticated approach, Koning (2000) used an ordered probit model to analyze the results of the Dutch football league. The author concluded that there is an advantage in home games and that the difference in the quality of the teams greatly influences the results obtained. This study also concluded that the balance of the Dutch league has not changed much since the 70s.

\section{Data and Methodology}

In our analysis we considered the classification of the Portuguese professional football league from season 1991/92 until season 2013/14 season (23 seasons). During this period, in the season of 2005/06, the Portuguese league suffered a two-team reduction, from 18 to 16 teams. The concentration techniques we used to measure the competitive balance in both subperiods were the Concentration Index $\left(\mathrm{C}_{k}\right.$ Index $)$, the Herfindahl-Hirschman Index (HHI) and the standard deviation of league points (SDLP). Since football is a sport where draws are possible, and it is feasible for a team with less wins than another to occupy a higher place in the league's final standings, we applied the methodology to points won by teams and not to the number or percentage of wins.

\section{Concentration Index $-C_{k}$}

According to Cabral (1994), the Concentration Index, $\mathrm{C}_{k}$, is most commonly used in academic studies and market research. It is defined as the sum of market shares of the $k$ th-first firms in a market, with the $\mathrm{N}$ firms competing ordered by decreasing market shares. In leagues' standings, the teams are naturally classified in decreasing order of points achieved. The index varies from $\mathrm{k} / \mathrm{N}$, where $\mathrm{N}$ is the total number of firms, and all have exactly the same share of the market (minimum concentration) and 1, where there is only one firm with all the market (monopoly - maximum concentration). Knowing that, when applied to firms and markets, these indices use market shares in their calculations, we had to adapt them in order to apply them to the study of competitiveness in sport leagues. Concerning this, it was necessary to select a 
ratio that could represent the "share" of each team. We used two different techniques. In the first one, we considered the "share" as the percentage of points a team makes relatively to the maximum number of points it could gain along the championship (Koning 2000). In this approach, the share points of a champion is given by the following expression:

$$
s_{1}(a)=\frac{P_{1}}{2 W(N-1)}
$$

(we used (a) and (b) to differentiate the applied methods), where $\mathrm{P}$ represents the points obtained, $\mathrm{W}$ the points awarded by victory and $\mathrm{N}$ the number of teams in the league. This expression is only valid to the first placed team, since it is theoretically possible for a champion to win all matches, but, in this scenario, the maximum points the second placed team in that league could achieve must include two defeats. Therefore, the concentration ratio we used is given by the quotient between the points obtained by the top $\mathrm{K}$ teams and the points that they could have gained, knowing that the maximum points are team specific (or place specific). The concentration ratio is formally defined as:

$$
C_{k}(a)=\frac{\sum_{k=1}^{k} P_{k}}{k W(2 N-K-1)}
$$

If the concentration ratio is high, the top $k$ th-teams did not lose many points to weaker teams. The second ratio we used as a measure of a team share was the percentage of points each team obtained relatively to the total points obtained in the league.

$$
S_{k}(b)=\frac{P_{k}}{\sum_{k=1}^{N} P_{k}}
$$

And the $\mathrm{C}_{k}(\mathrm{~b})$ concentration ratio is defined as:

$$
C_{k}(b)=\sum_{k=1}^{k} s_{k}(b)
$$

We also used an adjusted $\mathrm{C}_{k}$ to correct the changes in the league size. This adjustment gives us the $\mathrm{C}_{k}$ Index of Competitive Balance.

$$
C_{k} I C B=\left(\frac{C_{k}}{k / N}\right) \times 100
$$




\section{Herfindahl - Hirschman Index - HHI}

Firstly developed by Hirschman (1964), the HHI represents the concentration level within a market and its bounds are between $1 / \mathrm{n}$ (minimal concentration) and 1 (maximal concentration). In sport economics research, the HHI was modified by Depken (1999), to analyze competitive balance using winning percentages and by Michie and Oughton (2004), using percentages of points. Contrary to the $\mathrm{C}_{\mathrm{k}}$ index, that only takes into account $k$ firms, the $\mathrm{HHI}$ uses the information of all $\mathrm{N}$ competing firms/teams. The expression is given by:

$$
H H I=\sum_{k=1}^{N} s_{k}^{2}
$$

where $s_{k}^{2}$ represents the share of the $k$ th team squared.

\section{Standard Deviation League Points}

The use of this methodology was developed by Scully (1989) and Quirk and Fort (1992) and was modified by Humphreys (2002) to the standard deviation of winning percentages. The standard deviation of league points (SDLP) is calculated using the points each team achieves in a season and the average points in a league with $\mathrm{N}$ teams,

$$
S D L P=\sqrt{\frac{\sum_{k=1}^{N}\left(P_{k}-\overline{T P}\right)^{2}}{N}}
$$

where $P_{k}$ is the individual team points in a season, $\overline{T P}$ are the average points in that season and $\mathrm{N}$ is the number of teams. If SDLP increases, the competitive balance decreases.

\section{Results}

Concentration Index $-C_{k}$

This index measures the inequality between the top $k$ teams and the remaining ones. A reduction in the index reflects an increase in the competitive balance and a weakening in the domination by the top $k$ teams. We chose to calculate the $\mathrm{C} 1$, in order to analyze how dominant the champions have been, and the $\mathrm{C} 3$, since the Portuguese football is dominated by the so-called "3 Grandes" (Big 3). As an example of this dominance, in the 23 seasons in analysis, only one time has the champion of the league not been one of these 3 teams. 
Figure 1. Results Concentration Index C3

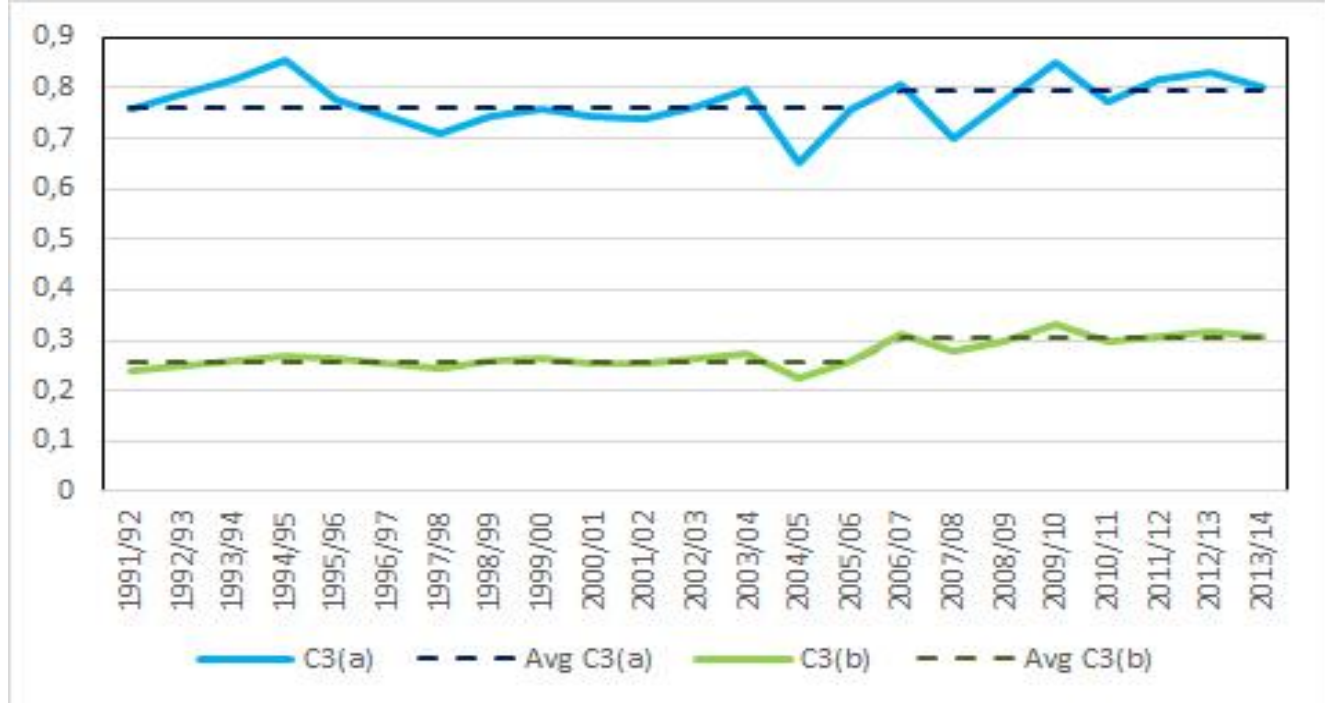

Source: Authors' estimations.

Figure 1 represents the $\mathrm{C} 3$ index, calculated from the two different methodologies. The season of the reduction was in 2006/07 and both in C3(a) and in $\mathrm{C} 3(\mathrm{~b})$ it is possible to observe an increase in the indices, summarized by the increase in the average of the indices of both periods (first period with 18 teams and second period with 16 teams). This means that the top 3 teams in the final standings won relatively even more points after the reduction than before.

Figure 2. Results Concentration Index C1

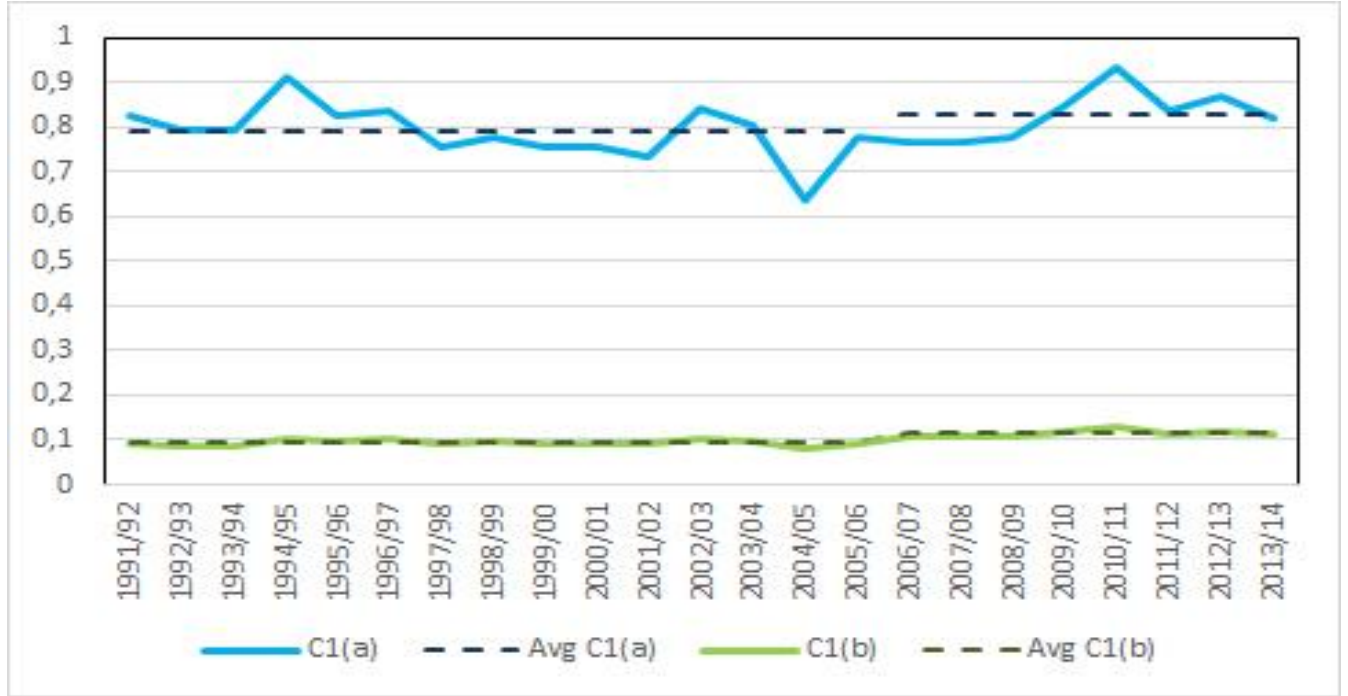

Source: Authors' estimations.

The $\mathrm{C} 1$ indices are represented in Figure 2. Also in these indices it is possible to observe an increase in their values after the 2006/07 reduction. The averages for the second period, with 16 teams, increase in both methodologies. 
Even though this is clearly more evident in the $\mathrm{C} 1$ (a) situation, in $\mathrm{C} 1$ (b) the increase has a magnitude of $21.64 \%$.

Figure 3. Results Concentration Index C3IBC

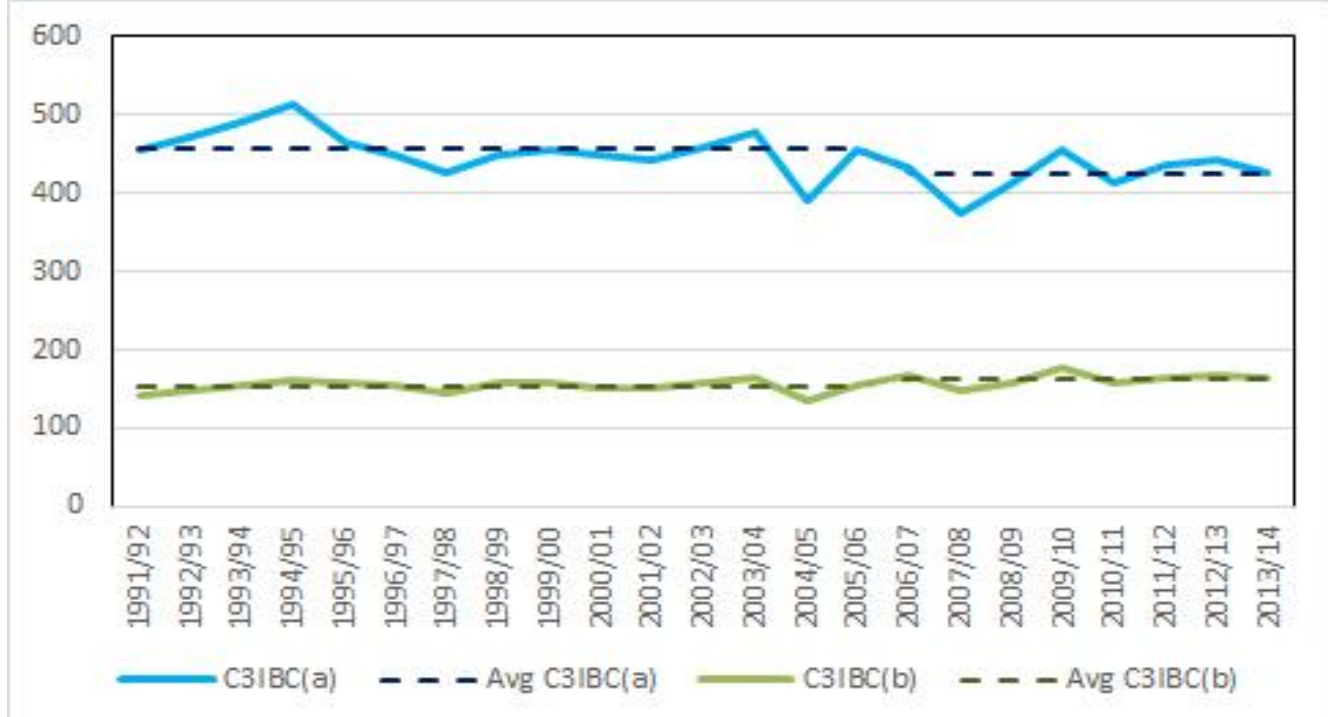

Source: Authors' estimations.

When we corrected the C3 indices to accommodate the change in the number of teams (Figure 3), we obtained contradictory results. The method (a) indicated an improvement in the league's competitive balance after the two teams reduction, while method (b) gave us the opposite result of a decrease in competitiveness.

$H H I$

This index measures the level of concentration of points between all the teams. Like in the $\mathrm{C} k$, an increase in the competitive balance occurs when the index contracts.

Figure 4 presents the values for the HHI(a) and for the HHI(b). Identically to the C3ICB indices scenario, we obtained contradictory results. On the one hand, the HHI(a) indicates that the two-team reduction actually improved the competitiveness of the league, but on the other hand, the HHI(b) points a result in which the competitive balance is in fact worse than in the past. 
Figure 4. Results HHI

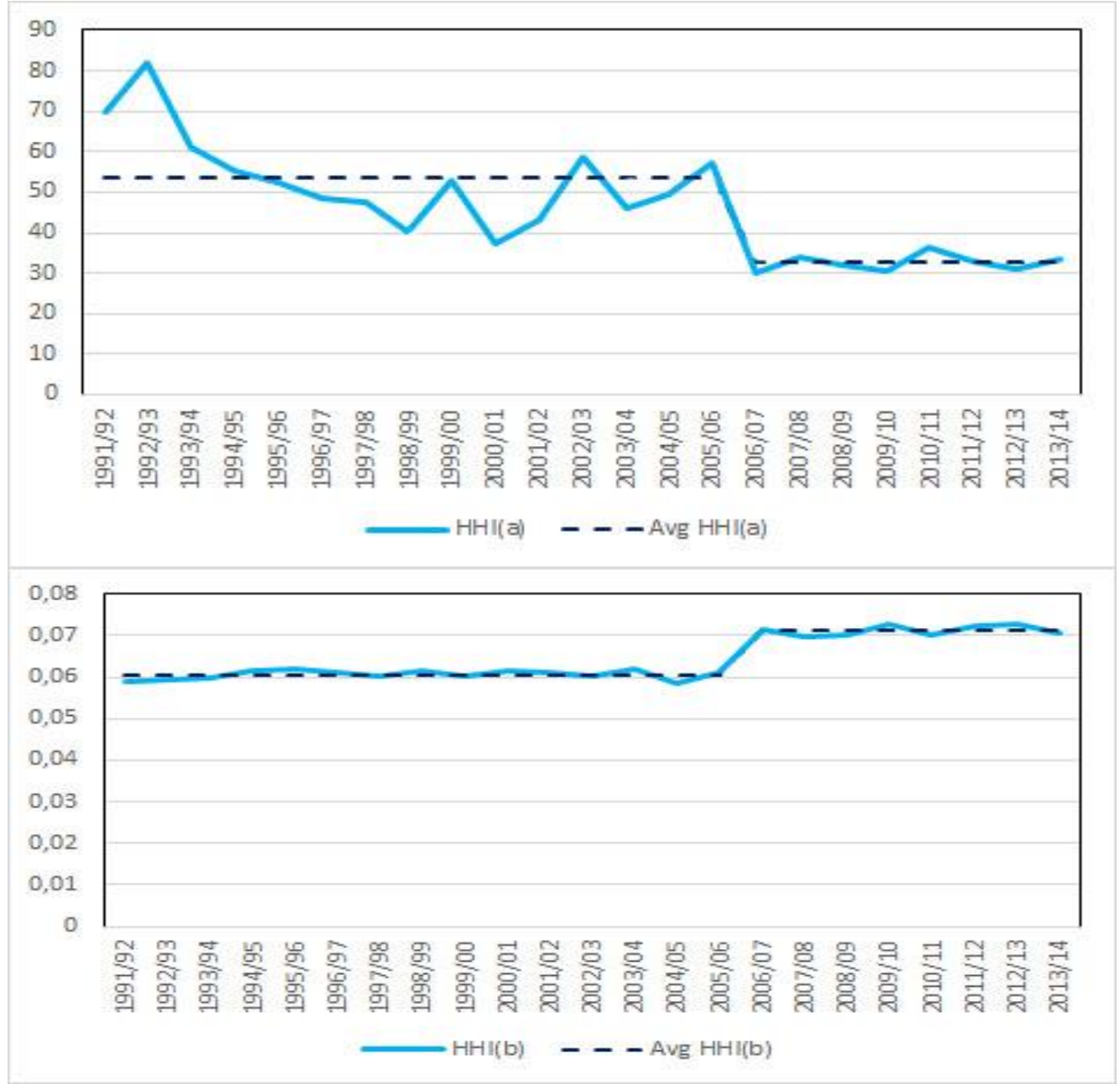

Source: Authors' estimations.

\section{Standard Deviation League Points}

In this index we could analyze how dispersed were the teams' points relatively to the average points obtained by all the teams in the league. Since higher dispersion in the points means higher differences between top and bottom teams, a reduction in the index reflects an increase in the competitiveness. 
Figure 5. Results SDLP

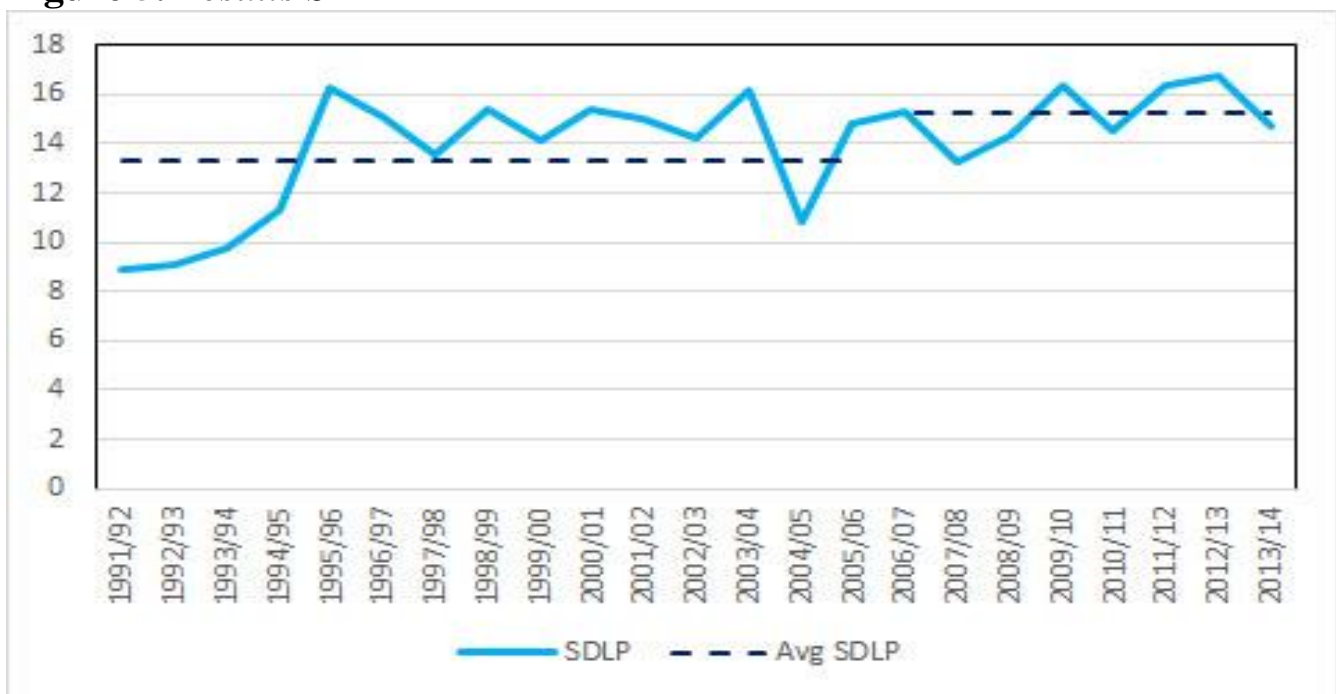

Source: Authors' estimations.

It's possible to observe in Figure 5 that the teams' reduction led to an increase in the SDLP Index, meaning that the point's dispersion grew in relation to the league's previous format.

\section{Mann-Whitney $U$}

To verify if the results obtained were statistically significant, we conducted a nonparametric test, the Mann-Whitney test, which allowed us to compare the groups of the two periods without making the assumption that values were normally distributed. The null hypothesis of this test states that the medians of the two samples are identical.

In Table 1 we could see that only three of the nine indices utilized display a non-significant difference in the groups' distributions (and in the groups averages), before and after the reduction. This is the case in the C1(a), C3(a) and SDLP indices. In all of them, the data show an increase in the indices, but the results are not statistically significant, so we cannot say that the reduction had any effect towards a less competitive balance. But we also cannot say that the competitiveness has improved. 
Table 1. Hypothesis Test Summary - Mann-Whitney $U$

\begin{tabular}{|l|c|c|l|}
\hline \multicolumn{1}{|c|}{ Index } & Comp. Balance & Sig. & Decision \\
\hline C1(a) & Reduction & 0.158 & Retain null hyp. \\
\hline C1(b) & Reduction & 0.000 & Reject null hyp. \\
\hline C3(a) & Reduction & 0.075 & Retain null hyp. \\
\hline C3(b) & Reduction & 0.000 & Reject null hyp. \\
\hline C3IBC(a) & Improvement & 0.004 & Reject null hyp. \\
\hline C3IBC(b) & Reduction & 0.003 & Reject null hyp. \\
\hline HHI(a) & Improvement & 0.000 & Reject null hyp. \\
\hline HHI(b) & Reduction & 0.000 & Reject null hyp. \\
\hline SDLP & Reduction & 0.115 & Retain null hyp. \\
\hline
\end{tabular}

Note: Asymptotic significances are displayed. The significance level is 0.05 .

Source: Authors' estimations.

There are four indices $(\mathrm{C} 1(\mathrm{~b}), \mathrm{C} 3(\mathrm{~b}), \mathrm{C} 3 \mathrm{IBC}(\mathrm{b})$ and $\mathrm{HHI}(\mathrm{b}))$ that point to a weakening in the competitive balance following the reduction, and whose effects are significant. But conversely, there are two indices (C3IBC(a) and HHI(a)) that indicate an improvement in the competitiveness and that are equally statistically significant.

\section{Conclusions}

In this paper we have discussed how the balance in competition in the Portuguese football league was affected by a reduction in two teams occurred in the 2006/07season. That reduction in the number of contenders was, in many forums, announced by the Portuguese football authorities as a measure to improve the league's competitiveness. We used several indices regularly applied in the literature in order to study the effect of a transition from an 18 to a 16 teams league. We concluded that this measure did not improve the degree of competiveness expected by the league executives. On the contrary, more indices showed the opposite effect, that is, a reduction on the competitive balance, and others led us to the conclusion that this step had no significant effect at all.

It was not our objective to make a validation of the indices utilized or point out which one is the most correct, but since some of them gave us contradictory results, one of our next steps might be to evaluate which is the most accurate sport index to measure competitiveness.

The Portuguese football is not a widely studied area, even though it is an industry that generates millions of Euros and attracts millions of supporters. This paper also has the objective to be a first step to more sophisticated economic analyses on this phenomenon. 


\section{References}

Bennett R, Fizel J (1995) Telecast deregulation and competitive balance: NCAA Division I football. American Journal of Economics and Sociology 54: 183-199.

Borland J, Macdonald R (2003) Demand for sport. Oxford Review of Economic Policy 19: 478-502.

Cabral L (1994) Economia Industrial [Industrial Economics]. Lisboa: McGraw-Hill.

Canes M (1974) The social benefits of restrictions on team quality. Government and the Sports Business. Washington, DC: Brookings Institution.

Depken C (1999) Free-agency and the competitiveness of Major League Baseball. Review of Industrial Organization 14: 205-217.

Dorian O, Ryan M, Weatherston C (2007) Measuring competitive balance in professional team sports using the Herfindahl-Hirschman Index. Review of Industrial Organization 31(4): 289-302.

Fort R, Maxcy J (2003) Comment on competitive balance in sports leagues: An introduction. Journal of Sports Economics 4: 154-60.

Hirschman A (1964) The paternity of an index. The American Economic Review 54(5): 761.

Horowitz I (1997) The increasing competitive balance in Major League Baseball. Review of Industrial Organization 12: 373-87.

Humphreys B (2002) Alternative measures of competitive balance in sports leagues. Journal of Sports Economics 3(2): 133-148.

Jones D, Rawnsley P, Switzer A (2014) Annual Review of Football Finance $\left(23^{\text {th }}\right.$ edn.). Manchester: Deloitte Sports Business Group.

Koning R (2000) Balance in competition in Dutch soccer. Journal of the Royal Statistical Society Series-The Statistician 49: 419-431.

Michie J, Oughton C (2004) Competitive Balance in Football: Trends and Effects. Research Paper No. 2. London: University of London, Football Governance Research Centre.

Mizak D, Stair A, Rossi A (2005) Assessing alternative competitive balance measures for sports leagues: A theoretical examination of standard deviations, Gini coefficients, the index of dissimilarity. Economics Bulletin 12(5): 1-11.

Noll R (1991) Professional basketball: economic and business perspectives. In PD Staudohar, JA Mongan (eds). The Business of Professional Sports. Chicago: University of Illinois Press, p. 18-47.

Quirk J, El-Hodiri M (1974) The economic theory of a professional sports league. Government and the Sports Business. Washington, DC: Brookings Institution.

Quirk J, Fort R (1992) Pay Dirt: The Business of Professional Team Sports. Princeton, NJ: Princeton University Press.

Schmidt M, Berri D (2001) Competitive balance and attendance: The case of Major League Baseball. Journal of Sports Economics 2: 145-67.

Scully G (1989) The Business of Major League Baseball. Chicago: University of Chicago Press.

Stefani R (1980) Improved least squares football, basketball, and soccer predictions. IEEE Transactions on System, Man and Cybernetics 10: 116-123.

Szymanski S (2003) The economic design of sporting contests. Journal of Economic Literature 41: 1137-87.

Zimbalist A (2002) Competitive balance in sports leagues: An introduction. Journal of Sports Economics 3(2): 111-121. 